UCRL --53639

Abstract

sumatra

FEMA has broad roles in the management of disasters potentially involving substantial amounts of radioactive contamination. These could be either peacetime or wartime disasters. A meeting was held in March, 1985 to see if there are any research contributions that FEMA might reasonably make in the area of radioprotective drugs that would substantially enhance its ability to perform its mission. The other federal agencies presently sponsoring research in the field were represented at the meeting. A few selected researchers also participated to provide complementary viewpoints. Activities of a modest scale that FEMA might undertake were identified, as were larger scale activities that might be undertaken in the event of long-term, major funding-level increases for FEMA.

(2) references 
REPORT DOCUMENTATION PAGE

\begin{tabular}{l|l|}
\hline 1. REPORT NUMBER & GOVT ACCESSION NO. \\
\hline
\end{tabular}

4. TITLE (mo SubHitio)

$\therefore$ TYPE OF REPORT A PEPIOD COVERED

RADIOPROTECTIVE DRUGS: A SYNOPSIS OF CURRENT RESEARCH AND A PROPOSED RESEARCH PLAN FOR THE FEDERAL EMERGENCY MANAGEMENT AGENCY

7. AUTHOR(O)

Robert Hickman and Lynn Anspaugh

Final Report

6. PERFORMING ORG. REPORT NLMBEA UCRL -53639

8. CONTRACT OR GRANT NUMBER(s)

EMW-E-0883

9. PERFOAMING ORGANIZATION NAME AND ADORESS

Lawrence Livermore National Laboratory P.0. Box 808

Livermore, $C A 94550$

11. CONTROLLING OFFICE NAME AND ADDRESS

FEMA

Washington, DC 20472

T4. MONITORING AGENCY NAME ADDRESS(II flftorent from Controlline Ollice)

10. PROGRAM ELEMENT, PROJECT, TASK AREA S WORK UNIT NIJMBERS

24310

REPORT DATE

April 1985

13. NUMBER OFFAGE:

27

T5. SECURITY CLASS. fup thie repori,

Unclassified

15e. DECLASTIEICATION DOWNGRADING SCHEQULE

16. DISTRIBUTION STATEMENT (of thio Roport)

Approved for public release: Distribution unlimited

17. DISTRIBUTION STATEMENT (ol the ebetract entered Ir. Block 20, $/$ dilforent from Report)

10. SUPPLEMENTAFY NOTES

19. KEY WORDS (Continue on reveree aldo II nocessary and identily by block number)

Radioprotectors

Chemical Radiation Protection

Radiation Chemistry

Radiation Biology

Radiation Therapy

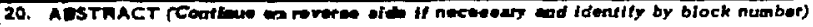

FEMA has broad roles in the management of disasters potentially involving substantial amounts of radioactive contamination. These could be either peacetime or wartime disasters. A meeting was held in March, 1985, to see if there are any research contributions that FEMA might reasonably make in the area of radioprotective drugs that would substantially enhance its ability to perform its mission. The other federal agencies presently sponsoring research in the field were represented at the meeting. A few selected researchers also 
participated to provide complementary viewpoints. Aotivities of a modest scale that FEMA might undertake were identified, as were larger scale activities that might be undertaken in the event of long-term, major funding-level increases for FEMA. 
PEMA has broad roles in the management of disasters potentially involving substantial amounts of radioactive contamination. These could be either peacetime or wartime disasters. A meeting was held in March, 1985 to see if there are any research contributions that FEMA might reasonably make in the area of radioprotective drugs that would substantially enhance its ability to perform its mission. The other federal agencies presently sponsoring research in the field were represented at the meeting. A few selected researchers also participated to provide complementary viewpoints. Activities of a modest scale that FEMA might undertake were identified, as were larger scale activities that might be undertaken in the event of long-term, major funding-level increases for FEMA.

\section{DISCLAIMER}

This report was prepared as an sccount of work sponsored by an agency of the United States Government. Neither the United States Government nor any anency thereof, nor any of their bility for the accuracy, completenew, or unefulnees, or asumes any legal linbility or tesponi. proces diecloed, or representa that it use would of noy information, apparatus, product, or ence herein to any specific commercial produch, procest infringe privately owned rights. Refermanufacturer, or aberwixe doen not neceeturily consti mendation, or favoring by the United Stated Government or imply its endoraement, recomand opinions of authors expresed berein do not necenterily any asency thereor. The views United States Government or any agency thereor. 
UCRL-53639

Distribution Category UC-41

\title{
Radioprotective Drugs: A Synopsis of Current Research and a Proposed Research Plan for the Federal Emergency Management Agency
}

\author{
R. Hickman and L. Anspaugh
}

Manuscript date: April 1985

Final Report

Interagency Agreemert EMW-0883, FEMA Work Unit 2431D

Prepared for Federal Emergency Management Agency

Washington, D.C. 20472

Approved for Public Release: Distribution Unlimited

\section{LAWRENCE LIVERMORE NATIONAL LABORATORY \\ University of California - Livermore, California $\cdot 94550$}


CONTENTS

Introduction ........................... 1

Pederal Programs to Develop Radioprotective Drugs . . . . . . . . . 3

Walter Reed Army Research Institute . . . . . . . . . . . . . 3

Armed Forces Radiobiology Research Institute . . . . . . . . . . 5

National Cancer Institute . . . . . . . . . . . . . . . 7

Department of Energy .. . . . . . . . . . . . . . . . 8

Discussion on the U.S. Program . . . . . . . . . . . . . . . 8

Suggested program for PEMA . . . . . . . . . . . . . . . . . . 10

Project Number 1: Establish a Lialson with the Walter Reed Army Research Institute, the Armed Porces Radiobiology Research Institute, and the National Cancer Institute ................. 10

Froject Number 2: Publish the FEMA-Sponsored Review of Radioprotective Drugs ir. the Open Literature . . . . . . . . . . . . . . . 11

Project Number 3: Evaluate Medical Intelligence Pertaining to What Other Countries, Particularly the USSR, Are Doing in the Field of Radioprotective Drugs ...................... . 11

Project Number 4: Assess Risk of a Radioprotective Drug . . . . . . 12

Project Number 5: Develop New Research Tools . . . . . . . . . . 13

Project Number 6: Perform Studies of the Metabolism

of the Aminothiols ...................... 13

Project Number 7: Perform studies of the Mechanisms of Toxicity of Aminothiols . . . . . . . . . . . . . . . . . . 14

Project Number 8: Perform Basic Research on the Fundamental

Mechanisms of the Action of Radiation . . . . . . . . . . . . 14

Acknowledgments . . . . . . . . . . . . . . . . . . . 15

References .............................. 16

Distribution List .......................... 17 
INTRODUCTION

FEMA has broad responsibilities at the federal level to plan and coordinate national responses to a wide variety of emergencies. Emergencies involving radioactive materials and exposure of people to their harmful (and potentially fatal) effects can be categorized broadly as wartime and peacetime.

Emergencies of the latter category would usually involve an accidental release of radionuclides. This could result from a transportation accident, malfunction of containment systems at a nuclear power plant or nuclear enrichment plant, or some other kind of accident.

The usual peacetime response would involve radiation monitoring, possibly evacuation of people, and perhaps cleanup operations. Most sleanup operations can be made simpler and less hazardous by waiting for the radionuclide(s) to decay. Nevertheless, there may be some instances where the best response would preclude a long cooling-off period, and where cleanup operations by qualified people should be performed as early as possible. Typically, when such a situation arises, emergency response people "take turns" so that no individual receives a radiation dose larger than that deemed acceptabla by national or international standards. Nevertheless, an occasion might possibly arise in which there would not be enough qualified people to perform the cleanup work. Under those circumstances, it could be beneficial to have a safe, effective radioprotective drug available to reduce the risk that these emergency response personnel would face.

In the case of a wartime emergency, we tend to direct our attention to the situation that might follow a nuclear attack on the country. For the moment, we exclude military personnel from the rationale, but their well-being will be considered later in the discussion. No one knows exactly what the conditions would be following a nuclear attack, but it is reasonable to assume that fallout from nuclear explosions would be present. That it would be essential to address this fallotit was the conclusion of the responsible people within the Federal Government when the National shelter survey for fallout protection was established decades ago. Iittle has happened to suggest that considerations of radioactive contamination could be ignored. There are two broad classes of civilians that we will want to protect (at least partially) with medication. 
Pirst consider the bulk of the population. Many of those who would need protection from fallout might very well have to take refuge in shelters that provide inadequate fallout protection. This would almost certainly be the case if an attack came today and the amount of warning time were short. Many buildings in urban areas could provide good fallout protection but few people are trained to take advantage of them. It might be possible to stockpile enough medication and distribute it in an emergency so that far fewer lives would be lost and the amount of radiation sickness would be reduced for those people exposed to sublethal doses of radiation. The difficulties in such a prog:"am are self-evident but this work is more an exploration of what might be rossible rather than development of a plan for what should be done.

The second broad category of civillans that would benefit from development of such a drug is composed of those described as keyworkers. Their responsibilities would be very similar to those of the peacetime emergency-response personnel. Keyworkers could be called upon to reestablish as quickly as possible critical life-support systems. Some examples might be restoration of some electric power, communications, and water supply. such people might have to go into a contaminated area to accomplish these tasks. Unlike the peacetime-accident scenario, there might not be a surplus of such people available since many parts of the country could be experiencing the same difficulties simultaneously. Using radiological survey techniques with some medication-induced protection from moderate radiation exposure, these keyworkers' actions could contribute to the saving of many lives.

It should be said here that such a medication does not exist and may never exist. While some compounds are known to confer radiation-protection factors of up to 2.7 in mice, little is known about their efficacy in man, but it is known, without exception, that the most effective ones are toxic to the point of being dekilitating. Furthermore, they have a short shelf life and must be administered intravenously. Also we do not know the details of how they work (i.e., their biological-protection mechanism).

The desirability of developing radioprotective substances was recognized decades ago, but drug development is very difficult and progress has been slow. In 1984, Oregon State University (OSU) was funded by FEMA to review progress in this field with the purpose of describing the current state of knowledge and identifying research possibilities. ${ }^{1}$ As a follow-up to that, a meeting was held in March, 1985 at which the programs of three federal 
organizations in this field were reviewed. The review report written by osu was discussed and opinions about the future were also obtained from a small, select group of people doing research in radioprotection. The substance of this meeting is covered in the remainder of this report.

FEDERAL PROGRAMS TO DEVELOP RADIOPROTECTIVE DRUGS

WALTER REED ARMY RESEARCH INSTITUTE

About 25 years ago, there was a large effort at Walter Reed Army Research Institute (WR) to develop drugs that would provide some protection to military personnel from the radiation effects of nuclear weapons. Over 4,000 chemicals were screened and many showed some protective ability in rats. The most promising [largest dose-reduction factor (DRF)] was s-3-(3-aminopropylamino) ethylphosphorothioic acid, dubbed WR-2721, which was discovered in 1965. There were substantial toxic side effects that made the drugs unsuitable for testing on humans. The work was terminated after a number of years for two reasons: (1) there was a dearth of promising research approaches to overcome the problems that have been encountered, and (2) greater demands were placed on the Institute to respond to the threatening effects of tropical diseases. Today, the WR Division of Experimental Therapeutics is made up of about 70 people, 35 of whom are professional level researchers. The funding level on radioprotective drug research is stable at about $\$ 3.5$ million per year, with the program having been restarted a few years ago. The Division maintains liaisons with NATO and other allies in this area and performs most, if not all, of the WR activities associated with drug development. This development starts with a blochemical rationale, and is followed by molecular modeling (for desired chemical structure and properties), synthesis, preclinical testing, and the first phase of clinical testing. Toxicity and radiobiological efficacy are determined through these activities. Before a drug is judged acceptable, it must meet the usual Food and Drug haministration guidelines. Large scale production of new drugs is normally performed by private industry.

The duration for which most drugs confer radioprotection is rather short, typically in the 15- to 30-minute range, and the drug must be taken before 
exposure to radiation to prevent harm. Radioprotective drugs such as the aminothiols and WR-2721 must be administered intraveneously because they will not pass through the gastrointestinal wall. Current objectives of the work are to increase the protective duration to four hours, to reduce the toxic side effects to the point that they do not impair a person's ability to perform highly demanöing tasks, to permit oral administration, and to provide protection against both gamma lays and neutrons. Most of the work right now focuses on WR-2721, and is particularly oriented toward permitting oral administration and a reduction in the nausea and vomiting associated with 1 t. While this drug has not been tested as a radioprotector in man, it has been administered to treat other diseases so its toxic effects are at least partially characterized. These goals are pursued through chemical modifications of the original structure. In addition, a dug of this kind should be compatible with other battlefleld medicines and should also be nonabusable. It is very desirable to have the radioprotection dose at least several times lower than the fatal dose from chemical toxicity. Finally, the drug should be capable of being self-administered repeatedly to provide prolonged protection for periods of time up to 2 weeks. Some drugs such as non-nitrogen sulfamates have been found to be orally effective, but their DRF ( 2 1.4) is not as high as that of $W_{R}-2721$ ( 2 2.5). To provide protection to the central nervous system, the drug must be capable of crossing the blood/brain barrier. In some combat situations, the lower body may be substantially shielded so that the critical region with respect to lethality may not be bone marrow but rather the lungs. One drug, WR-2121, gives better protection against neutrons than WR-2721, although the reasons for this are poorly understood.

The Institute recognizes that a better understanding of underlying biochemical mechanisms is required to guide the synthesis efforts. Work on encapsulating WR-2721 in a lipid matrix in the form of microspheres has been done to get the thiol past the acid conditions in the stomach and into the intestine where it can be absorbed. Pharmacokinetic studies have been very important and, as an adjunct to these, supportive analytical methods have been under development for four years. The initial steps in the metabolism of WR-2721 are now understood.

other compounds receiving special attention are WR-1065 'a thiometabolite of WR-2721) and WR-3689 (a methylated modification of WR-2721) because of 
their previously identified protective properties in mice. A new drug with improved protective performance in mice also is receiving special attention. Besides work on drugs that would be taken prior to an expected exposure, there is some work being done on those drugs that could be taken after exposure. These might repair cells or enhance natural repair mechanisms, or they might, like antiemetics, only provide symptomatic relief, which would allow acceptable performance for longer time periods following exposure. It should be noted that substantial performance loss can occir at exposure levels well below those that would be lethal.

Briefly, the accomplishments of the radioprotector program include improved assays on four of the more promising drugs, completion of pharmacokinetic studies in dogs, determination of chemical stabilities in plasma, and the carrying out of initial studies in monkeys.

The immediate goals involve continued work along lines that might lead to a suitable drug for clinical testing. Further understanding of metabolism is sought. Studies of bioavailability by oral administration (in rats) will be performed, and more development of assay methods is planned.

\section{ARMED FORCES RADIOBIOLOGY RESEARCH IMSTITUTE}

The Armed Forces Radiobiology Research Inst_tute (AFRRI) is a triservice military organization that is part or the Defense wuclear Agency. It has a total of about 230 employees and about 108 of these are working in the field of radioprotection. As with the program at walter Reed, the j.nterest is oriented toward nuclear battles and the main focus is on military personnel.

The program has a number of major components and has a very broad vision of what might be accomplished and how. clearly, radiation injuries would have to be managed, so the principles of dossimetry and triage would be applied. Besides the usual concern about cell damage leading to gastrointestinal and cardiovascular dysfunction or failure, the complicating factors of multiple injuries are also of concern. In particular, radiation exposure combined with bacterial invasion and other trauma is of interest.

Emphasis is given to immunologic and hematologic-enhancement factors. studies range, for example, from cell-mediated immunity in the former case to stem-cell physiology and hematopoletic enhancement by immunomodulators in ihe latter. 
Also, special attention is paid to factors that impair performance, be it a behavioral change or a decrement in motor function. The impairment may come from either the radiation exposure itself or from the radioprotector(s) that are administered. Not only is performance degradation measured, but the underlying causes ars sought, e.g., effects on neurons.

A basic research approach is taken to the issues of radiosensitization and radioprotection. Although the two issues are coupled, radiosensitivity is given less attention. There is a cellular radiobiology program that includes studies on DNA damage and repair, on the influence of stage in the cell cycle, and also on cell sulfhydryls. Electron-spin-resonance techniques are used to study chemical manifestations of radiation damage.

Radioprotection work is diverse. Studies include comparisons of the effects of different sulfhydryls with respect to postirradiation mortality, toxicity, protection against neutrons, and their role in immunoprotection. Nuciear magnetic resonance (NMR) techniques follow metabolism of radioprotectors. Nechanisms of radioprotectors are under investigation, including possible roles of DNA-synthesis inhibition, lipid peroxidation, and endogenous protective enzymes. The search continues for naturally occurring radioprotectors in the hope they might prove to be less toxic or easier to adninister.

It is believed that combinad treatments (in contrast to a combination of drugs in a radioprotective "cocktail") will be superior to a single treatment. Thus besides direct treatment, studies of the effects of nutrition, protection against infection, etc., are included in the program.

When WR-272l is used at its maximum dose, adding other drugs does not enhance its effectiveness. However, when used at lower doses so that its toxic side effects are reduced to manageable proportions, it could be true that some other compound might enhance the desirable effect or that some other chemical agent might be just as effective with respect to the DRF at the same level of toxicity.

Liposomes are being tested is delivery vehicles for radioprotective drugs. The immunological approach either with immunomodulators or immunoprotection is attractive because it appears to be inherently less toxic. Natural enzymes might be manipulated.

An important point, that protective mechanisms and toxic effects do not translate predictably between mice and dogs, was addressed. In fact, there 
are some differences even between mice and rats. Consequently, the radioprotectors that have proven best so far for mice or rats may not be as effective in man. By the same reasoning, some less effective compounds in mice could be superior in man. No testing has yet been done on humans, and while the biochemical behavior is often similar between different species, it is never the same. The difficulty arises because, in general, we do not know the detailed biochemical behavior in any species. For example, whereas WR-2721 is the best drug in mouse studies, other compounds are equally effective in logs, and although there are hypotheses, the reason is not known.

NATIONAL CANCER INSTITUTE

Work on radioprotective drugs at the National Cancer Institute (NCI) is performed under the auspices of the Radiation Modifier Research section. The grants program, which totals $\$ 50$ million annually, devotes about $\$ 2$ million to radiosensitizers and $\$ 0.5$ million to radioprotectors. The general purpose of the NCI work is to develop and understand therapeutic agents or even natural preventives for cancer.

The goals of the research are clearly quite different from those at either WR or AFRRI. Here, patients are under medical supervision. Some toxic side effects are tolerable, although undesirable. Intraveneous administration of drugs is preferred, to give the highest degree of control possible. specific tumors are to be made more sensitive to radiation, while the healthy tissue is protected. Deterioration in performance levels is not a consideration. Development of radioprotectors is not an end in itself but is rather an adjunct to cancer therapy.

NCI has a working group of scientists from the various cancer-research organizations around the country. All of the various disciplines required for work on radiosensitizers and radioprotectors are represented. Membership rotates in the group, that also advises NCI on potentially fruitful areas for research. The work is performed either under grants, contracts, or in-house funding. The most recent screening tests were performed under contract with Fox Chase Cancer Institute. There, drugs were administered intravenously to rats but none of the hundreds of drugs tested was found to be more effective than WR-2721. 
At present there is only one clinical trial on radioprotectors funded and it is a Phase I (maximum dose seeking) study at the University of Pennaylvania. There is still $a$ ban on WR-2721 for clinical testing, but it is expected to be lifted. The pharmacokinetics were unknown in man but recent advances in analytical techniques have permitted analyses of the compound and its metabolites in samples of human serum.

Glutathione, a naturally occurring aminothiol is known to scavenge free radicals. Experiments with compounds that have been known to increase glutathione within a cell were disappointing. Both $\mathrm{CoCl}_{2}$ and a compound dubbed OTz are known to increase glutathione levels by factors of 1.5 to 3 , but no added protection was found when the compounds were administered.

Along lines followed by ARRRI, the NCI has investigated compounds that increase the rate of hematopoietic recovery. These are not strictly radioprotectors because cell damage is not prevented, but since they increase the number of survivors, they are still called radioprotectors. The same is true of compounds affecting cell recovery in the gut. The protection or recovery of these two tissues is vital in radiotherapy.

The NCI research program possesses a synthesis capability, but at present there are few if any interesting leads on new compounds to make. There is a strong conviction, however, that more basic research on mechanisms needs to be performed, as contrasted with administering new compounds to mice, particularly as the results with mice do not necessarily carry over directly to man.

DEPARTMENT OF ENERGY

Although the Department of Energy (DOE) continues to support research in radiation biology, the listing of funded projects in Feference 1 did not reveal any having the development of radioprotective drugs as its goal. Thus, DOE was not asked to participate in the Harch, 1985 meeting.

\section{DISCUSSION ON THE U.S. PROGRAM}

The three federal institutes represented fund all the identified work in the U.S. While the end purpose of NCI differs from that of WR and AFRRI, the 
research methods used and the $k$ ind of information sought are guite similar.

There is a consensus that the most fruitful path at this time will likely be one that puts major emphasis on basic research. The biochemistry is extremely complex in itself. When one superimposes on this a fluence of ionizing radiation that randomly breaks up all molecules, the difficulty of finding one or a combination of drugs that would be radioprotective increases.

One of the problems in the past was that the purity of the drugs was unknown. At least some are known now to have been impure, so there are some incorrect data in the literature.

As was mentioned earlier, the mechanisms of radioprotection at the molecular level were recent $2 y$ reviewed. 1 It was judged by those present at the karch, 1985 meeting that this review, funded by FEMA through LLNL, was a valuable work that deserved broad distribution.

When a drug is administered to an animal, it is not always possible to know exactly where it goes and how much is present in the cells of each particular organ. Because some chemical transformations may be required to allow the drug access to a particular organ's cells, the importance of understanding the chemical kinetics of the transformations is apparent. This topic will be emphasized in the future.

Tools to undertake these kinds of investigations are only now beginning to be used with any degree of success. Further success in determining the details of much of the biochemistry will require substantial gains in the application of modern instrumental analysis.

We must also recognize the possibility that existing radioprotective drugs may have already achieved their maximum protective ability. The highest DRF achieved is about 2.5, which is also about the protective effect that the absence of oxygen achieves. It is possible that drugs only protect against the oxygen-mediated fixing of some radiation. age and that protection against the direct effects of radiation for imeurtant biological molecules is simply not possible, or is only possible with the aduition of other very different molecules that might, for example, selectively bind to DNA and protect it from direct effects.

To put the overall problem into a more easily understood frame of reference, it was recently reported that private industr: spends about $\$ 100$ million to develop a rather simple drug. 2 por development of more complex drugs, several times that amount may be required. Radioprotective 
drugs fall into this latter category. The current U.S. program described here 1. funded at level of about $\$ 5 \mathrm{million}$ per year. Thus it would be unrealiatic to expect rapid progress, A breakthrough of some kind might occur, but it cannot be predicted.

Consequently we also considered whether FEMA might obtain a relatively large leverage in this fleld by application of limited funding to une or a very few projects of unusual pronise. No specific projects were identified, but a few research areas are proposed in the next section.

\section{SUGGESTED PROGRAM FOR FEMA}

Some topics for additional research were proposed in Reference 1. These were reviewed at the March, 1985 meeting before the following Ideas were developed. This section outlines a suggested program for FEMA. Behind these suggestions are the following assumptions:

- FEMA will not have significant money available in FY 1986.

- FEMA needs to maintain some minimal program in radioprotection to keep abreast of activities of other agencies and other governments.

- FEMA may at some time in the future have sufficient money to obtain leverage in this field by supporting specific research. Discussed below, in order of decreasing priority and generally increasing cost, are eight specific projects in which FEMA might participate.

PROJECI NUMBER 1: ESTABLISH A LIAISON WITH THE WALTER REED ARMY RESEARCH INSTITUTE, THE ARMED FORCES RADIOBIOLOGY RESEARCH INSTITUTE, AND THE NATIONAL CANCER INSTITUTE

WR, AFRRI, and NCI have by far the most significant radioprotector research programs existing in this country and together have sufficient funding to exploit any novel, significant leads in the development of a new or improved drug. Thus, for a minimal program, it is essential that FEMA maintain contact with these institutes and keep abreast of their current activities. FEMA, GR, AFRRI, and NCI are all located in the washington, D.C. area, so this should be easy to accomplish, especially if someone were given that specific assignment. 
One particularly significant current activity is the NCI-sponsored, clinical Phase I trial of WR-2721 at the University of Pennsylvania. This drug and its derivatives represent the current state of the art in radioprotection and as the toxicity and efficacy in humans is not yet known, FEMA should probably follow these trials carefully. NCI-sponsored researeh, including clinical trials, is discussed in an open meeting twice a year. It seems important to have a FEMA representative at these meetings to keep informed of research in this important area.

PROJECT NUMBER 2: PUBLISH THE FEMA-SPONSORED REVIEW OF RADIOPROTECTIVE DRUGS IN THE OPEN LITERATURE

Participants in the workshop agreed that the FEMA-sponsored revilaw of radioprotective drugs was a real contribution to the scientific literature. of particular value was the information and suggestions it contained regarding the proposed mechanisms of several damage-fixing events and how such events might be altered by the elimination of oxygen or by the addition of specific chemicals. We therefore recommend that Reference 1 be prepared for publication in the open, refereed scientific literature.

PROJECT NUMBER 3: EVALUATE MEDICAL INTELLIGENCE PERTAINING TO WHAT OTHER COUNTRIES, PARTICULARLY THE USSR, ARE DOING IN THE EIELD OF RADIOPROTECTIVE DRUGS

In the course of the workshop discussions, it was mentioned several times that the USSR had distributad a radioprotective drug or mixhure of drugs to its population for civil defense purposes. The consensus of the group, based upon its current knowledge of available drugs, was that such information might be a propaganda (internal or external) ploy. Nevertheless, this is an area where PEMA's best interests would be served by acquiring some solid data. As the Department of Defense (DOD) has an existing medical intelligence apparatus presumably capable of tracking such activities, a worthwhile task would be to have someone undertake a specific evaluation of this information. 
PROJECT NUHBER 4: ASSESS RISK OF A RADIOPROTECTIVE DRUG

All known radioprotective drugs are quite toxic. Cne of the serious concerns about such drugs is that, if they were actually used under wartime conditions, drug recipients might be strongly tempted to use more than the recommended dose resulting in serious acute toxicity problems. Even if the recommended dose were not exceeded, there would also undoubtedly be many untoward reactions to the drug unless major improvements are forthcoming.

We also note here that the distribution and potential use of potassium iodide $(K I)$ as a blocking agent against the uptake of radioiodine by the thyroid has created a great deal of controversy in this country. As there is no doubt that $K I$ is very much less toxic than any of the currently available radioprotective drugs, we would anticipate that an attempt to distribute a raciioprotective drug on a large scale would engender a lengthy and acerbic public debate.

It would therefore be appropriate to consider very carefully both the potential risks and the benefits of distributing such a drug well before distribution might seriously be proposed. First, one should determine the likely distribution of radiation doses from a direct bomb busst and, second, that from fallout so that the number of casualties to be expected in the absence of radioprotective drugs can be estimated. In this analysis, distribution of radiation duses should be calculated carefully so that one can introduce a radioprotective factor to recalculate the number of casualties when radioprotective drugs are used. Depending upon the distribution of radiation doses from the two effects, the efficacy of the drug might conceivably range all the way from producing no effect at all (all radiation doses are already too high for protection to be effective) to providing complete protection (all radiation doses are within the range of efficacy of the drug).

This protective effect must then be balanced against the cost of the drug, and the risks of using such a drug, including toxic effects and the possibility of other undesirable side effects. Also to be considered in the risk evaluation is whether the drug could actually be distributed on short notice so as to be widely available (currently available radioprotective drugs must be taken before the radiation dose is delivered in order to be effective). 
PROJECT NUMBER 5: DEVELOP NEW RESEARCH TOOLS

Progress in research on the protective aminothiol drugs has been hampered by the lack of available methods of analysis for the administered drugs and their metabolic conversion products. Thus, there is still much to be learned of the kinetics and mechanisms of drug activation by the removal of a protective group, of drug inactivation by metabolic processes, and even of the tissue distribution of the drug as a function of time following administration. There is even speculation that aminothiol drugs might act indirectly by consuming oxygen carried by peripheral blood.

Some of the studies needed to resolve these and other questions are very basic and simple, but depend tetally upon an ability to measure concentrations of the relevant compounds in blood and tissue. Applicable analytical methods were not available until very recently. The existing methods, however, lack sensitivity and are rather laborious.

Some very exciting applications of NMR spectroscopy are just now beginning. By synthesizing radioprotective compounds that contain active components, such as carbon-13 and phosphorous-31, one can discover many new details of the metabolism of these compounds. These NMR applications are just now getting underway and show a great deal of promise.

FEMA might achieve some leverage by funding very specific, improved methods of analysis for the aminothiol drugs and by supporting studies of the mstabolism of aminothiols by NMR spectroscopy or other instrumental methods.

PROJECT NUMBER 6: PERFORM STUDIES OF THE METABOLISM OE THE AMINOTHIOLS

Assuming that improved investigative tools are developed, the next logical step will be to promote their application to studies of the metabolism of aminothiols. These studies are absolutely essential to future progress in the application of this most promising class of prosective drugs. Although these applications would probably proceed without any specific funding from FEMA, this might be a fruitful project for FEMA to join in with another federal agency to enhance the rate of progress. 
PROJECT NUMBER 7: PERFORM STUDIES OF THE MECHANISMS OF TOXICITY OF AUINCTHIOLS

The aminothiol drugs are toxic as well as radioprotective. The mechanisms leading to toxicity are, however, not known. obviously, these mechanisms would have to be thoroughly investigated before the aminothiols could be considered safe for large-scale, public distribution.

One interesting question that remains to be answered is whether the radioprotective and toxic effects are related to each other and perhaps inseparable. If the two effects should prove to be separable, one might be able to develop a "cocktail" of different drugs that would have additive protective effects but not additive toxic effects. FEMA could cosponsor this work with another agency.

PROJECT NUMBER 8: PERFORM BASIC RESEARCH ON MHE FUNDAMENTAL MECHANISMS OF THE ACTION OF RADIAIION

The basic problem underlying development of a radioprotective drug is the lack of understanding of how radiation affects cellular components at the atomic and molecular level. progress in developing radioprotective drugs so far has largely been due to serendipity and some very hard work in following up the few available leads. It does not appear likely, however, that the continuation of such research will lead to dramatic increases in radioprotective efficacy.

An interesting side issue that has already been raised is whether we might already have reached a theoretical limit in our ability to achieve radioprotection. Obviously, this cannot be addressed until a great deal more is understood of the basic mechanisms accompanying the action of radiation. Much research has already gone, and is going, into this field and it is not likely that FEMA could ever play a key role without the expenditure of very large sums of money. This is probably not even a desirable activity for FEMA because the apparatus is already well in place to manage such research and there is probably adequate money to pursue all truly interesting lsads. 


\section{ACKNOWLEDGMENTS}

The people who attended and contributed to the meeting described in this report deserve much credit. Representatives from the federal agencies participated voluntarily, giving generously of their time without additional compensation. We gratefully thank them and the others who traveled long distances so they could take part. These people are Dave Davidson (Walter Reed Army Research Institute), Joe Weiss (Armed Forces Radiobiology Research Institute), Tom Strike (National Cancer Institute), John Livesey (Oregon state University), Janet Rasey (University of Washington), Darrell Brown (Fox Chase Cancer Institute), and of course the FEMA sponsors of this work, Dave Bensen and Carl siebentritt. 
1. J. C. Livesey, D. J. Reed, and L. F. Adamson, "Chemical protection Against Ionizing Radiation, Pederal Emergency Management Agency, Work Unit 2432D, Oregon State University, Corvallis, OR, August 1984.

2. W. Williams, "Glory Days End for Pharmaceuticals," The New York Times, February 24, 1985, Business Section, p. 1 . 
1 copy unless otherwise noted

Federal Emergency Management Agency

David Bensen - Room 619

Emergency Management Research Division

Office of Civil preparedness

National preparedness programs Directorate

Washington, D.C. 20472

Federal Emergency Management Agency (3)

Chief, Emergency Management Research Div. - Room 619

office of Civil preparedness

National Preparedness Programs Directorate

Washington, D.C. 20472

National Emergency Training Center

Learning Resource Center - Building N

Federal Emergency Management Agency

16825 South Seton Ave.

Emmitsburg, MD 21727

Defense Technical Information Center (DTIC) (12)

Cameron Station

Alexandria, VA 22314

Assistant Director

Energy and Natural Resources

office of Science and Technology Policy

Executive office Building

Washington, D.C. 20500

Office of Joint Chiefs of staff

Pentagon

Washington, D.C. 20301

Director

Defense Nuclear Agency

Col. David Auton/Thomas Kennedy

Washington, D.C.

Assistant secretary of the Army (RD\&A)

Deputy ASA for (RRD\&A)

Washington, D.C. 20310

Chief of Engineers

Department of Army

DAEN-RDZ-A

Washington, D.C. 20360 


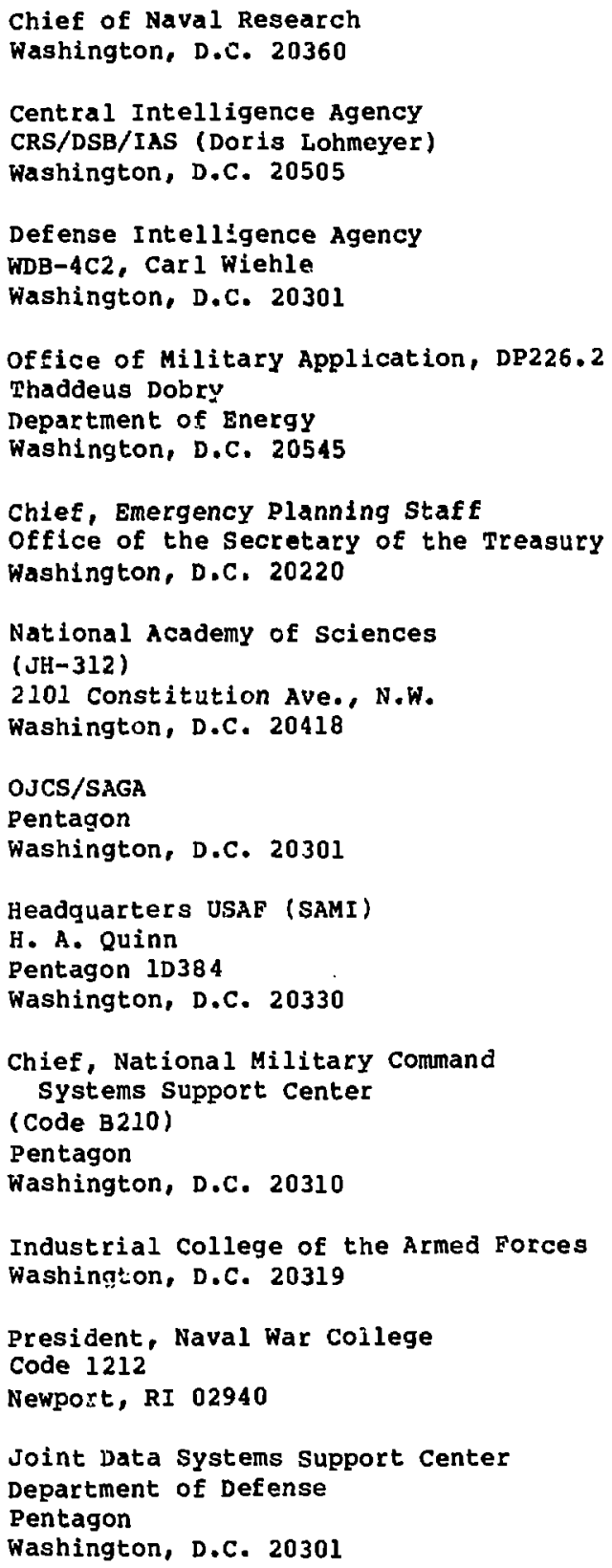




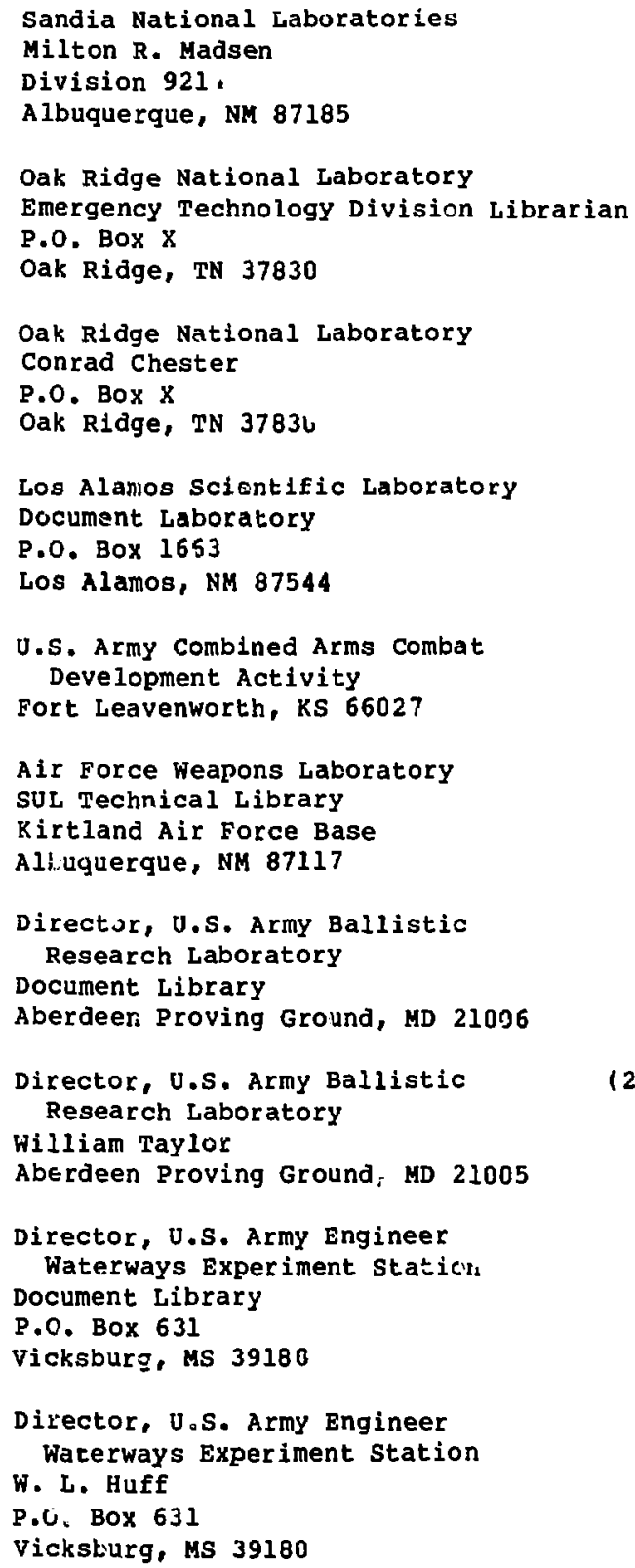




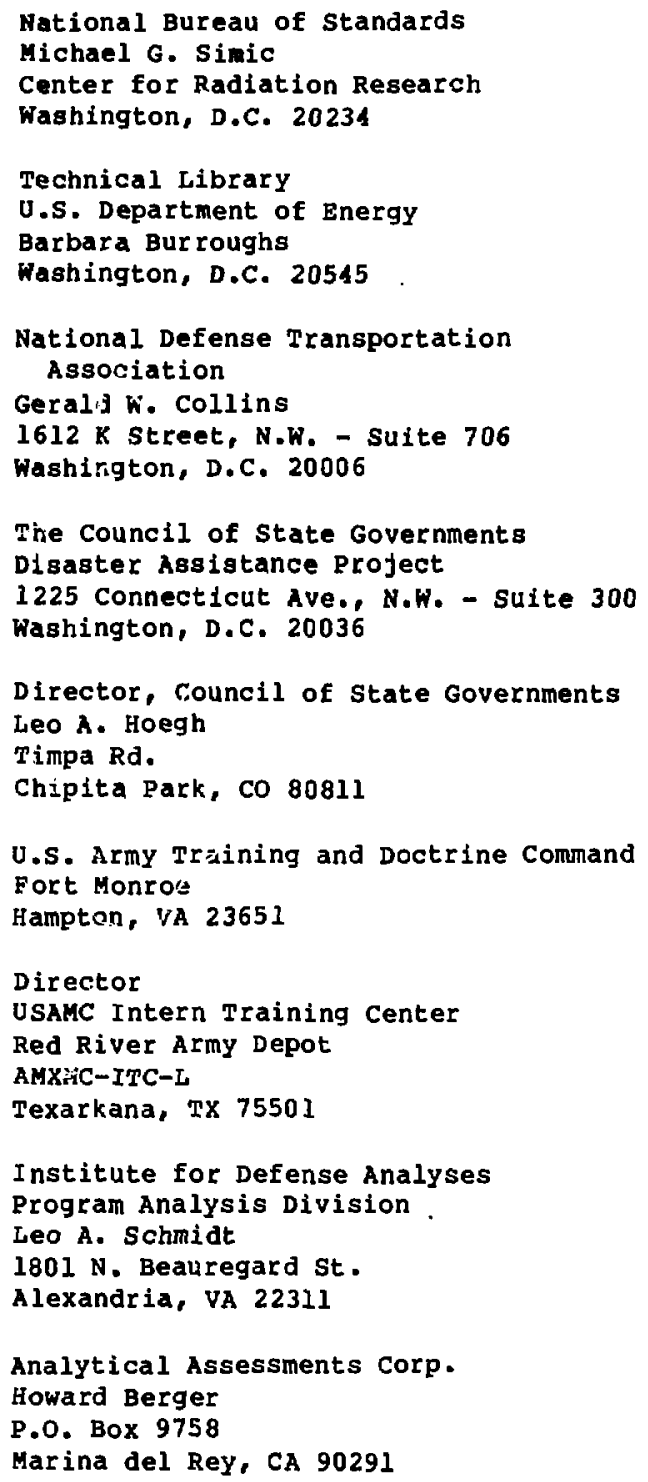




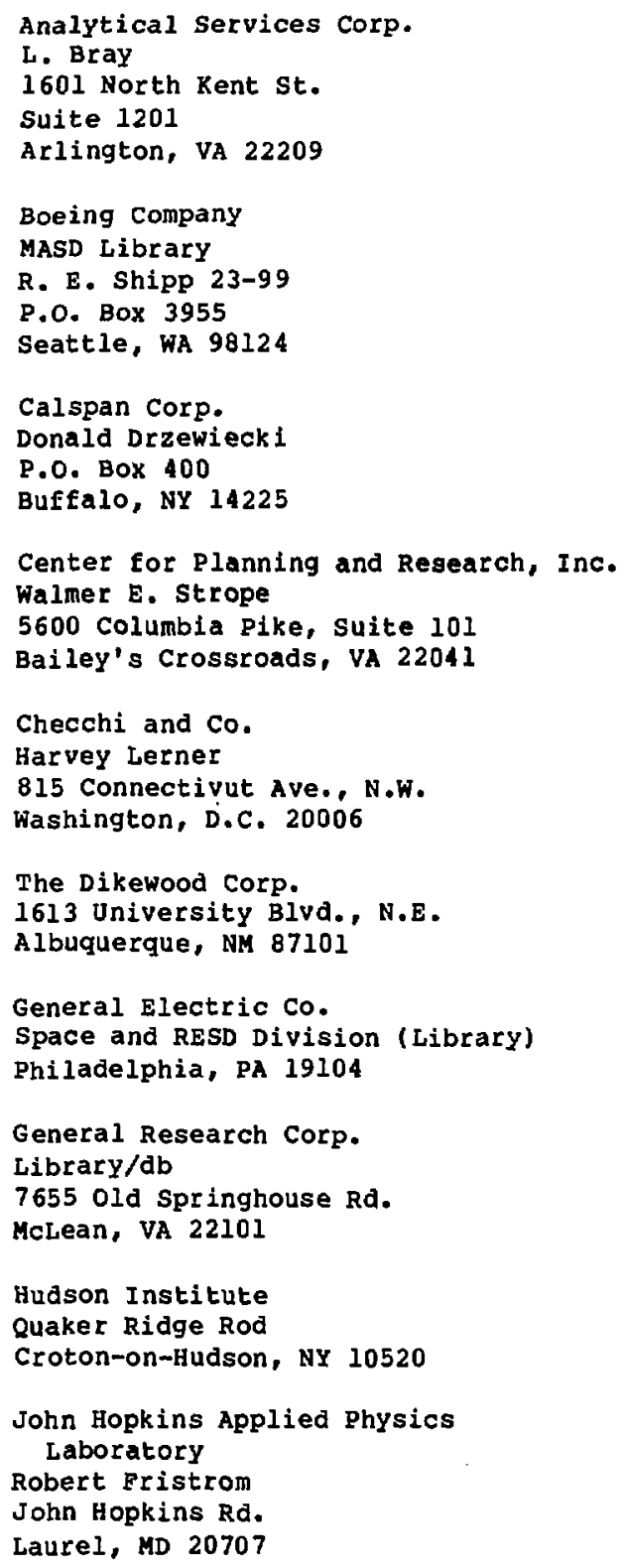




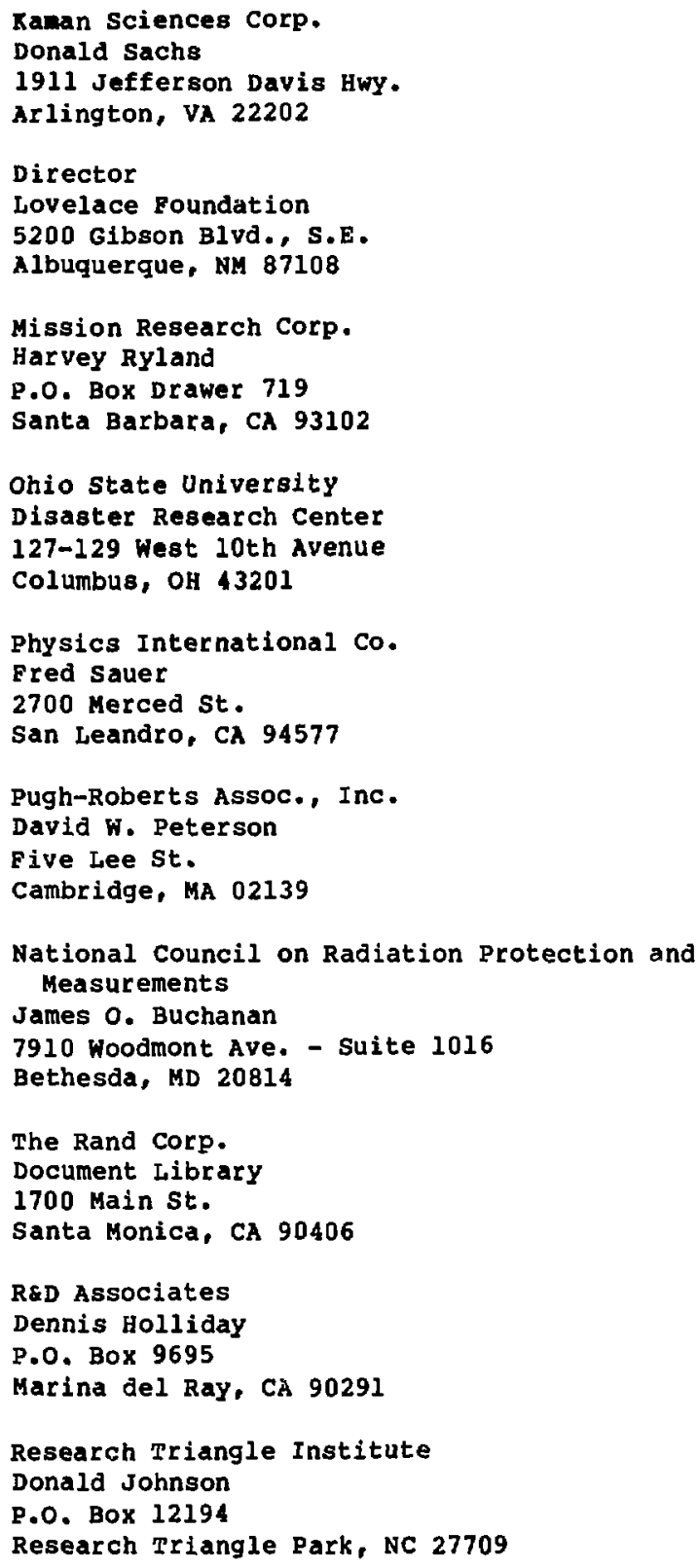




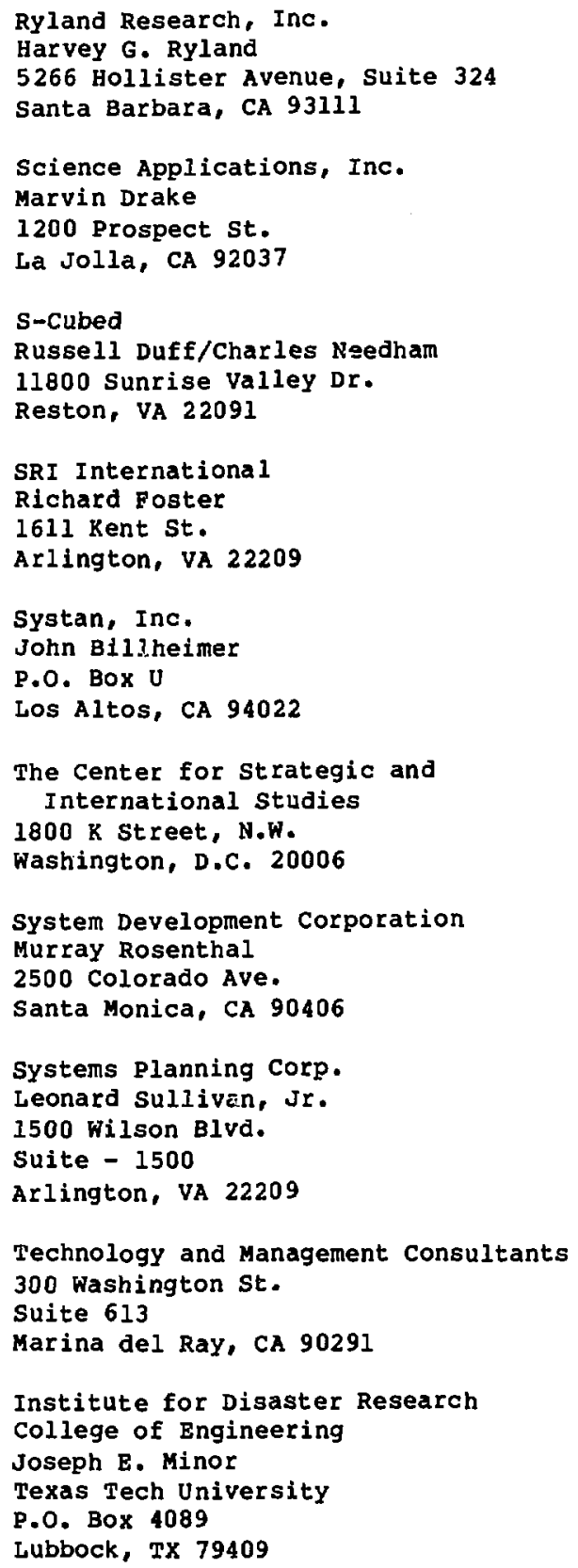




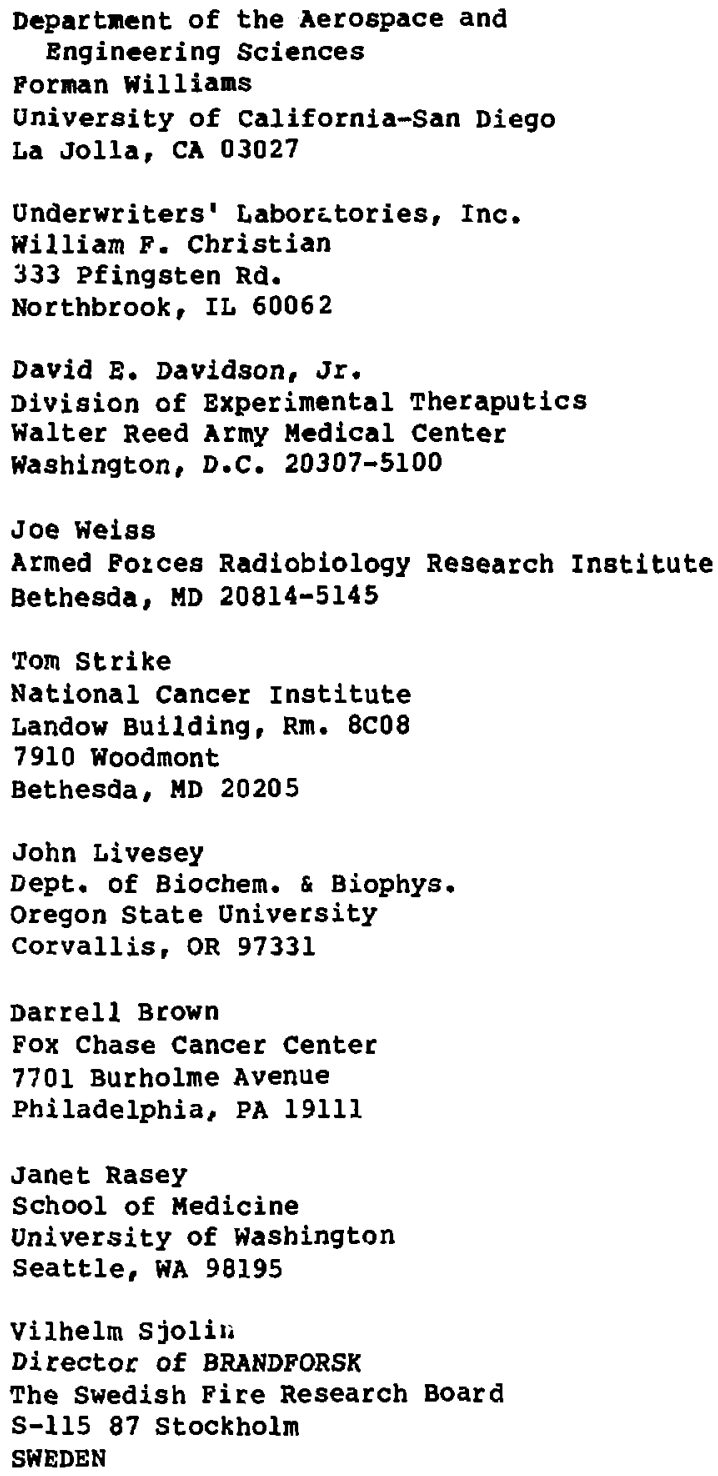


Secretaire d'Administration

Ministere de l'Interieur

Direction Generale de la

Protection Civile

rue de Louvain, 1

1000 Brussels

BELGIUM

Canadian Defence Research Staff

K. N. Ackles

2450 Massachusetts Ave., N.พ.

Washington, D.C. 20008

Director

Civilforsvarsstyrelsen

stockholmsgade 27

2100 Copehagen 0

DENMARK

Direction 'de la securite civile

Ministere de 1 'Interieur

18 Rue Ernest Cognac

92 Levallois (Paris)

FRANCE

Bundesministerium des Innern

Graurheindorfer Strasse 198

5300 Bonn 1

WEST GERMANY

Ministry of Social services

11 spartis st.

Athens

GREECE

Almannavarnir Rikisins

Reykjavik

ICELAND

Stato Maggiore Difesa Civile

Centro studi Difesa Civile

Rome

ITALY

Civil Emergency Planning

Directorate

North Altantic Treaty organization

1110 NaTO

BELGIUM 


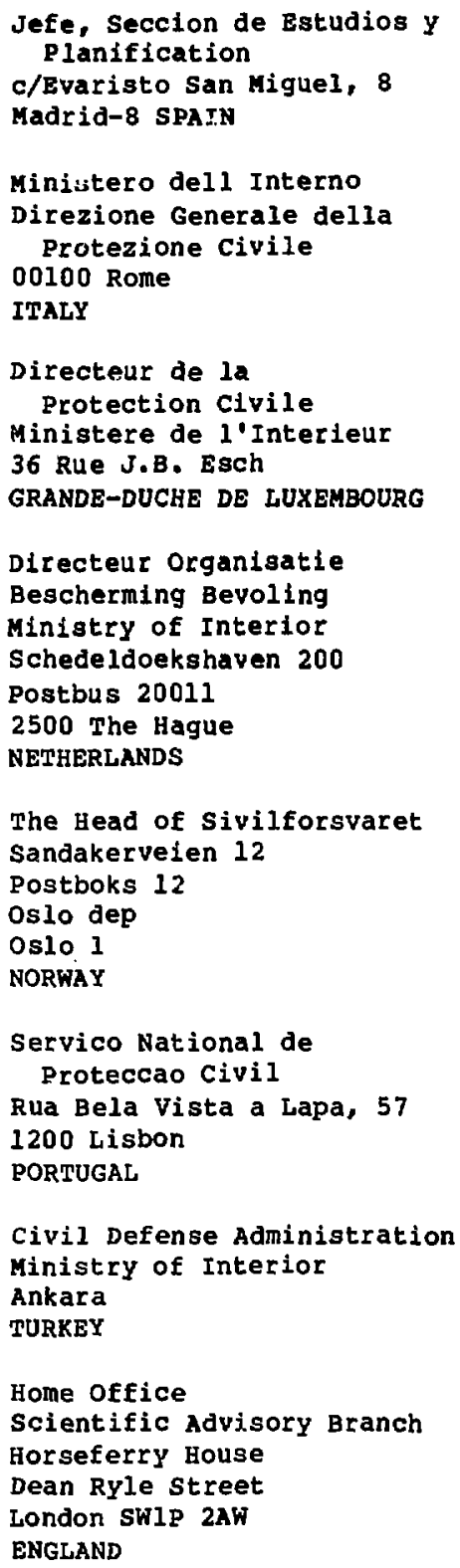




\section{P.G. Seeger}

Forschungsstelle für

Brandschütztechnik

University of Karlsruhe (TH)

$75 \mathrm{Kar}$ lsruhe 21

postfach 63380

WEST GERMANY 